\title{
COMPOSIÇÃO MINERAL DE GRÃOS DE TRIGO SUBMETIDOS A DOSES DE SULFATO DE AMÔNIO E TRINEXAPAC-ETIL ${ }^{1}$
}

\author{
Marcelo Curitiba Espindula², Marcela Campanharo ${ }^{3}$, \\ Valterley Soares Rocha ${ }^{2}$, Pedro Henrique Monnerat ${ }^{4}$, Luiz Fernando Favarato ${ }^{2}$
}

\begin{abstract}
MINERAL COMPOSITION OF WHEAT GRAINS SUBJECTED TO AMMONIUM SULFATE AND TRINEXAPAC-ETHYL RATES

Grain mineral composition is important for the establishment of appropriate fertilizer levels, as well as to define the nutritional quality of food and physiological quality of seeds. The objective of this study was to evaluate the effect of ammonium sulfate (AS) and trinexapac-ethyl rates on mineral composition of wheat grains (Triticum aestivum L.) cv. Pioneiro. The experiment was carried out in Viçosa, Minas Gerais State, Brazil, from June to October 2006. The treatments consisted of five AS rates ( $150 \mathrm{~kg} \mathrm{ha}^{-1}, 300 \mathrm{~kg} \mathrm{ha}^{-1}, 450 \mathrm{~kg} \mathrm{ha}^{-1}, 600 \mathrm{~kg} \mathrm{ha}^{-1}$, and $\left.750 \mathrm{~kg} \mathrm{ha}^{-1}\right)$ combined with four trinexapac-ethyl rates $\left(0 \mathrm{~g} \mathrm{ha}^{-1}\right.$, $62.5 \mathrm{~g} \mathrm{ha}^{-1}, 125 \mathrm{~g} \mathrm{ha}^{-1}$, and $\left.187.5 \mathrm{~g} \mathrm{ha}^{-1}\right)$. The experiment was arranged in a randomized block design with four replications. AS rates increased the concentrations of total-N (protein), Ca, $\mathrm{S}, \mathrm{Cu}$, and $\mathrm{Zn}$ and decreased the concentrations of $\mathrm{P}, \mathrm{K}$, and $\mathrm{Mn}$ (at AS rates above $457 \mathrm{~kg} \mathrm{ha}^{-1}$ ). The $\mathrm{Mg}$ and Fe concentrations were not influenced by AS rates. Trinexapac-ethyl increased total-N, P, and $\mathrm{Mn}$; reduced $\mathrm{Ca}$; and had no influence on the concentrations of $\mathrm{K}, \mathrm{S}, \mathrm{Cu}, \mathrm{Zn}, \mathrm{Mg}$, and $\mathrm{Fe}$. It can be concluded that AS application improves the nutritional quality of grains, while the use of the growth retardant trinexapac-ethyl has no influence on its mineral composition.
\end{abstract}

KEY-WORDS: Triticum aestivum L.; nutrition; growth retardant.

\section{INTRODUÇÃO}

A produtividade das culturas e a qualidade dos produtos são afetadas pela disponibilidade de nutrientes nos agroecossistemas (Schulthess et al. 1997, Ortiz-Monasterio et al. 2007). Nos campos de produção de sementes, a composição mineral destas influi na formação do embrião e das estruturas de reserva, afetando sua germinação. Portanto, a concen-

\section{RESUMO}

A composição mineral de grãos é importante para a definição da qualidade nutricional do alimento e qualidade fisiológica das sementes, devendo ser considerada no estabelecimento dos níveis adequados de adubação. Neste contexto, objetivou-se, com este estudo, avaliar o efeito de doses de sulfato de amônio (SA) e de trinexapac-etil, na composição mineral de grãos de trigo (Triticum aestivum L.) cv. Pioneiro. O experimento foi desenvolvido em Viçosa (MG), no período de junho a outubro de 2006. Os tratamentos foram cinco doses de SA (150 kg ha ${ }^{-1}, 300 \mathrm{~kg} \mathrm{ha}^{-1}, 450 \mathrm{~kg} \mathrm{ha}^{-1}, 600 \mathrm{~kg} \mathrm{ha}^{-1} \mathrm{e}$ $\left.750 \mathrm{~kg} \mathrm{ha}^{-1}\right)$, combinadas com quatro doses de trinexapac-etil $\left(0 \mathrm{~g} \mathrm{ha}^{-1} ; 62,5 \mathrm{~g} \mathrm{ha}^{-1} ; 125 \mathrm{~g} \mathrm{ha}^{-1}\right.$; e 187,5 $\left.\mathrm{g} \mathrm{ha}^{-1}\right)$. O experimento foi instalado em delineamento de blocos casualizados, com quatro repetições. As doses de SA aumentaram as concentrações de $\mathrm{N}$-total (proteína), Ca, S, Cu e Zn e diminuíram as concentrações de P, K e Mn (acima de $457 \mathrm{~kg} \mathrm{ha}^{-1} \mathrm{de} \mathrm{SA}$ ). Os teores de $\mathrm{Mg}$ e Fe não foram influenciados pelas doses de SA. O trinexapacetil promoveu aumento de N-total, $\mathrm{P}$ e Mn e redução de Ca. Os teores de $\mathrm{K}, \mathrm{S}, \mathrm{Cu}, \mathrm{Zn}, \mathrm{Mg}$ e Fe não foram influenciados pelo redutor. Concluiu-se que a aplicação de SA melhora a qualidade nutricional de grãos, enquanto a utilização do redutor de crescimento trinexapac-etil não influencia na composição mineral dos mesmos.

PALAVRAS-CHAVE: Triticum aestivum L.; nutrição; redutor de crescimento.

tração de nutrientes nos grãos deve ser considerada no estabelecimento de níveis adequados de adubação, para cada cultura.

O nitrogênio (Gomes Júnior et al. 2005) e o enxofre (Coelho et al. 2001) desempenham efeito direto no teor de proteínas nos grãos, por serem constituintes dos aminoácidos. Ainda, o fornecimento destes nutrientes, via fertilização, pode influenciar na composição mineral de grãos, como o milho,

1. Trabalho recebido em ago./2009 e aceito para publicação em dez./2010 (nº registro: PAT 6928/ DOI: 10.5216/pat.v40i4.6928).

2. Universidade Federal de Viçosa, Departamento de Fitotecnia, Viçosa, MG, Brasil.

E-mails: curitibaespindula@yahoo.com.br,vsrocha@ufv.br,1favarato@yahoo.com.br.

3. Fundação de Amparo à Pesquisa do Espírito Santo, Gerência de Pesquisa e Difusão, Vitória, ES, Brasil. E-mail: marcelacampanharo@gmail.com.

4. Universidade Estadual do Norte Fluminense Darcy Ribeiro, Laboratório de Fitotecnia, Campos dos Goytacazes, RJ, Brasil. E-mail:phmonnerat@yahoo.com.br. 
onde a adubação nitrogenada aumenta os teores dos nutrientes minerais $\mathrm{P}, \mathrm{K}, \mathrm{Ca}, \mathrm{Mg}, \mathrm{S}, \mathrm{Cu}, \mathrm{Fe}, \mathrm{Mn}$ e Zn (Ferreira et al. 2001).

Gramíneas como o trigo (Triticum aestivum L.), por não serem beneficiadas pela fixação biológica de nitrogênio com a mesma eficiência das leguminosas, precisam obter $\mathrm{N}$ do solo e de fertilizantes. No entanto, é importante destacar que a utilização de doses elevadas do nutriente, visando ao aumento da produtividade, resulta em maior desenvolvimento vegetativo e, consequentemente, em acamamento das plantas, interferindo, negativamente, no rendimento e qualidade dos grãos (Buzetti et al. 2006).

Substâncias sintéticas, denominadas redutores de crescimento, têm sido estudadas para o controle do acamamento, em culturas agrícolas como o trigo (Stachecki et al. 2004), arroz (Buzetti et al. 2006, Alvarez et al. 2007) e soja (Linzmeyer Junior et al. 2008), entre outras. Estas substâncias atuam como sinalizadores químicos, na regulação do crescimento e desenvolvimento de plantas. Normalmente, ligam-se a receptores na planta e desencadeiam uma série de mudanças celulares, as quais podem afetar a iniciação ou modificação do desenvolvimento de órgãos ou tecidos (Rademacher 2000).

Dentre os redutores utilizados atualmente, o trinexapac-etil tem apresentado resultados promissores na redução da estatura das plantas de trigo (Matysiak 2006, Berti et al. 2007, Zagonel \& Fernandes 2007, Espindula et al. 2009, Espindula et al. 2010). Este redutor de crescimento pertence ao grupo das acilciclohexanoedionas, as quais inibem dioxigenases dependentes do 2-oxoglutarato, na etapa 3 da biossíntese de giberelina. Acilciclohexanoedionas são, estruturalmente, similares ao 2-oxoglutarato e são, portanto, inibidoras da atividade da dioxigenase por competição pelo sítio de ligação do cosubstrato 2-oxoglutarato (Rademacher 2000).

Os redutores que atuam sobre a estatura de plantas são, normalmente, antagonistas às giberelinas e agem modificando o metabolismo destas, mas, tam- bém, podem agir sobre outros processos metabólicos (Heckman et al. 2002, Gobi et al. 2005, Viana et al. 2008) e, consequentemente, interferir na composição mineral dos grãos.

Neste contexto, objetivou-se, com este trabalho, avaliar o efeito de doses de sulfato de amônio (SA) e de trinexapac-etil, na composição mineral de grãos de trigo (Triticum aestivum L.) cv. Pioneiro.

\section{MATERIAL E MÉTODOS}

O experimento foi desenvolvido na Estação Experimental Prof. Diogo Alves de Mello da Universidade Federal de Viçosa, Viçosa, MG (20 $45^{\circ}$ 'S, $42^{\circ} 51^{\prime}$ 'W e altitude de $650 \mathrm{~m}$ ), de junho a outubro de 2006. Aárea utilizada para implantação do experimento foi cultivada, nos anos anteriores à instalação do experimento, com soja (verão) e trigo (inverno). O delineamento adotado foi em blocos casualizados, com quatro repetições, em esquema fatorial $5 \times 4$, constituído pela combinação de cinco doses de sulfato de amônio (150 kg ha', $300 \mathrm{~kg} \mathrm{ha}^{-1}$, $450 \mathrm{~kg} \mathrm{ha}^{-1}, 600 \mathrm{~kg} \mathrm{ha}^{-1}$ e $\left.750 \mathrm{~kg} \mathrm{ha}^{-1}\right)$, contendo, respectivamente, $30 \mathrm{~g} \mathrm{ha}^{-1}, 60 \mathrm{~g} \mathrm{ha}^{-1}, 90 \mathrm{~g} \mathrm{ha}^{-1}, 120 \mathrm{~g} \mathrm{ha}^{-1} \mathrm{e}$ $150 \mathrm{~g} \mathrm{ha}^{-1}$ de nitrogênio e $33 \mathrm{~kg} \mathrm{ha}^{-1}, 66 \mathrm{~kg} \mathrm{ha}^{-1}, 99 \mathrm{~kg} \mathrm{ha}^{-1}$, $132 \mathrm{~kg} \mathrm{ha}^{-1}$ e $165 \mathrm{~kg} \mathrm{ha}^{-1}$ de enxofre, com quatro doses do redutor de crescimento trinexapac-etil (4-ciclopropril (hidróxi) metileno-3,5-dioxociclohexano carboxilato de etila) $\left(0 \mathrm{~g} \mathrm{ha}^{-1}\right.$; 62,5 $\mathrm{g} \mathrm{ha}^{-1} ; 125 \mathrm{~g} \mathrm{ha}^{-1}$ e 187,5 $\left.\mathrm{g} \mathrm{ha}^{-1}\right)$. Cada parcela foi constituída por sete linhas, com $5 \mathrm{~m}$ de comprimento, espaçadas $0,18 \mathrm{~m}$ entre si. A área útil da parcela $\left(2,20 \mathrm{~m}^{2}\right)$ foi constituída pelas três linhas centrais, sendo eliminado meio metro $(0,5 \mathrm{~m})$, em ambas as extremidades das linhas.

O solo da área experimental foi classificado como Argissolo Vermelho-Amarelo e seus atributos químicos e físicos foram determinados na camada 0-0,2 m, segundo Embrapa (1997) (Tabelas 1 e 2).

O preparo do solo foi realizado por meio de uma aração e duas gradagens. A adubação de semeadura foi realizada utilizando-se a dose de $250 \mathrm{~kg} \mathrm{ha}^{-1}$ do formulado comercial 08-28-16 e a dose complementar de nitrogênio foi aplicada utilizando-se o

Tabela 1. Atributos químicos determinados na camada 0-0,2 $\mathrm{m}$ do Argissolo Vermelho-Amarelo utilizado no experimento (Viçosa, MG, 2006).

\begin{tabular}{|c|c|c|c|c|c|c|c|c|c|c|c|c|c|c|c|c|}
\hline $\mathrm{pH}$ & $\mathrm{MO}$ & $\mathrm{P}$ & $\mathrm{K}$ & $\mathrm{Ca}^{2+}$ & $\mathrm{Mg}^{2+}$ & $\mathrm{Al}^{3+}$ & $\mathrm{H}+\mathrm{Al}$ & SB & $\mathrm{CTC}(\mathrm{t})$ & CTC(T) & $\mathrm{V}$ & $\mathrm{Cu}$ & $\mathrm{Zn}$ & $\mathrm{Fe}$ & $\mathrm{Mn}$ & B \\
\hline $\mathrm{H}_{2} \mathrm{O}$ & $\mathrm{g} \mathrm{kg}^{-1}$ & $\mathrm{mg} \mathrm{dm}^{-3}$ & \multicolumn{8}{|c|}{$\mathrm{cmol}_{\mathrm{c}} \mathrm{dm}^{-3}$} & $(\%)$ & & 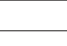 & $\mathrm{g} \mathrm{dm}$ & & \\
\hline 5,6 & 17,3 & 22,9 & 0,27 & 2,3 & 0,5 & 0,0 & 3,47 & 3,07 & 3,07 & 6,54 & 47 & 3,8 & 17,1 & 172 & 108 & 0,29 \\
\hline
\end{tabular}

$\mathrm{pH}\left(\mathrm{H}_{2} \mathrm{O}-1: 2,5\right) ; \mathrm{Ca}^{2+}, \mathrm{Mg}^{2+}$ e Al ${ }^{1+}$ : extrator $\mathrm{KCl} 1 \mathrm{~mol} \mathrm{~L}^{-1} ; \mathrm{P}, \mathrm{K}, \mathrm{Cu}, \mathrm{Zn}, \mathrm{Fe}$ e Mn: extrator Mehlich 1; $\mathrm{H}+$ Al: extrator acetato de cálcio 0,5 mol L-1 a pH 7,0. 
Tabela 2. Atributos físicos determinados na camada 0-0,2 $\mathrm{m}$ do Argissolo Vermelho-Amarelo utilizado no experimento (Viçosa, MG, 2006).

\begin{tabular}{ccccc}
\hline Argila & Silte & Areia fina & Areia grossa & Classe textural \\
\cline { 1 - 4 } & & $\mathrm{g} \mathrm{kg}^{-1}$ & & \\
\hline 460 & 190 & 120 & 230 & Argila \\
\hline
\end{tabular}

sulfato de amônio como fonte. Todo o $\mathrm{N}$ foi aplicado na semeadura.

A semeadura foi realizada no dia 12 de junho de 2006, sendo utilizadas sementes de trigo 'Pioneiro'. Esta cultivar é recomendada para o cultivo na região do Brasil Central, possui porte médio e é responsiva à adubação nitrogenada, entretanto, apresenta altos índices de acamamento, sob doses elevadas do nutriente.

Quando as plantas atingiram o estádio F8 da escala de Feecks e Large (Sobrinho \& Souza 1983), o redutor de crescimento trinexapac-etil foi aplicado. As aplicações foram realizadas utilizando-se pulverizador costal, à pressão constante de $2,5 \mathrm{Bar} \mathrm{pol}^{-2}$, pressionado por $\mathrm{CO}_{2}$ comprimido, com duas pontas de jato tipo leque (XR 110.015), espaçadas em $0,5 \mathrm{~m}$. Foi aplicado volume de calda equivalente a $150 \mathrm{~L} \mathrm{ha}^{-1}$.

A colheita foi realizada em 14 de outubro de 2006, quando as sementes das plantas estavam no estádio de maturação fisiológica. Foram determinados os teores de $\mathrm{N}, \mathrm{P}, \mathrm{K}, \mathrm{Ca}, \mathrm{Mg}, \mathrm{S}, \mathrm{Cu}, \mathrm{Zn}$, $\mathrm{Fe}$ e $\mathrm{Mn}$ nos grãos. Os teores de N, P e K foram determinados a partir do extrato da digestão sulfúrica: o N-orgânico, pelo método de Nessler; o P por colorimetria, utilizando-se o método do molibdato; e o K por fotometria de chama. $\mathrm{O} \mathrm{Ca}, \mathrm{Mg}, \mathrm{Cu}, \mathrm{Zn}, \mathrm{Fe}$ e Mn foram quantificados por espectrofotometria de absorção atômica e o S por turbidimetria, utilizando-se $\mathrm{BaCl}_{2}$ e goma arábica.

Os dados foram submetidos à aplicação do teste $\mathrm{F}$, na análise de variância. As variáveis significativamente influenciadas pelas doses de nitrogênio e/ou redutor de crescimento foram submetidas a análises de regressão. Os modelos foram escolhidos segundo as equações com melhores ajustes, confirmados pelos maiores valores dos coeficientes de determinação $\left(\mathrm{r}^{2} / \mathrm{R}^{2}\right)$ e pela significância dos coeficientes de regressão $\left(\beta_{\mathrm{i}}\right)$ e do teste $\mathrm{F}$ da regressão, ambos a $5 \%$ de probabilidade.

\section{RESULTADOS E DISCUSSÃO}

A Tabela 3 contém informações estatísticas referentes às representações gráficas (Figura 1 e 2) utilizadas para facilitar a visualização dos resultados.

O nitrogênio total, nos grãos, aumentou linearmente, com o acréscimo das doses de SA e de trinexapac-etil (Figura 1A). A resposta para as doses de SA foi semelhante à encontrada para trigo, na Síria (Ryan et al. 2008) e no Brasil (Trindade et al. 2006), em resposta a doses de N. Este aumento se deve à maior absorção do nutriente, devido à maior disponibilidade de $\mathrm{N}$ no solo e, consequentemente, à maior translocação para os grãos. $\mathrm{O}$ aumento do $\mathrm{N}$ nos grãos, em função das doses de trinexapac-etil, se deve ao melhor enchimento de grãos, promovido pela redução dos níveis de acamamento (resultados não apresentados) e pelas alterações morfológicas das plantas, pois estas ficam com arquitetura mais adequada para aproveitar os recursos do meio, especialmente radiação solar (Zagonel \& Fernandes

Tabela 3. Equações estimadas, coeficientes de determinação e coeficientes de variação das concentrações de nutrientes, nos grãos de trigo submetidos às doses de sulfato de amônio (SA) e trinexapac-etil (RED) (Viçosa, MG, 2006).

\begin{tabular}{llrr}
\hline \multicolumn{1}{c}{ Nutriente } & \multicolumn{1}{c}{ Equação $^{1}$} & $\begin{array}{c}\text { Coeficiente de } \\
\text { determinação }\left(\mathrm{r}^{2} / \mathrm{R}^{2}\right)\end{array}$ & $\begin{array}{c}\mathrm{CV} \\
(\%)\end{array}$ \\
\hline $\mathrm{N}$ total & $\hat{\mathrm{Y}}=1,3263+0,0007 \mathrm{SA}+0,0007064 \mathrm{RED}$ & 0,97 & 4,4 \\
$\mathrm{P}$ & $\hat{\mathrm{Y}}=1,9069-0,0002 \mathrm{SA}+0,0007258 \mathrm{RED}$ & 0,87 & 5,4 \\
$\mathrm{~K}$ & $\hat{\mathrm{Y}}=4,8661-0,0005 \mathrm{SA}$ & 0,93 & 5,7 \\
$\mathrm{Ca}$ & $\hat{\mathrm{Y}}=0,3115+0,0002 \mathrm{SA}-0,0001488 \mathrm{RED}$ & 0,94 & 6,1 \\
$\mathrm{Mg}$ & $\hat{\mathrm{Y}}=1,3055$ & - & 5,6 \\
$\mathrm{~S}$ & $\hat{\mathrm{Y}}=70,9106+0,0310 \mathrm{SA}$ & 0,88 & 7,4 \\
$\mathrm{Cu}$ & $\hat{\mathrm{Y}}=0,1118+0,000037 \mathrm{SA}$ & 0,88 & 10,8 \\
$\mathrm{Zn}$ & $\hat{\mathrm{Y}}=0,8353+0,0002 \mathrm{SA}$ & 0,78 & 13,5 \\
$\mathrm{Fe}$ & $\hat{\mathrm{Y}}=0,9762$ & - & 45,3 \\
$\mathrm{Mn}$ & $\hat{\mathrm{Y}}=1,0224+0,00064 \mathrm{SA}-0,0000007 \mathrm{SA}^{2}+0,00039 \mathrm{RED}$ & 0,82 & 6,5 \\
\hline
\end{tabular}

${ }^{1}$ Todos os coeficientes de regressão $\left(\beta_{\mathrm{i}}\right)$ são significativos a $5 \%$. 

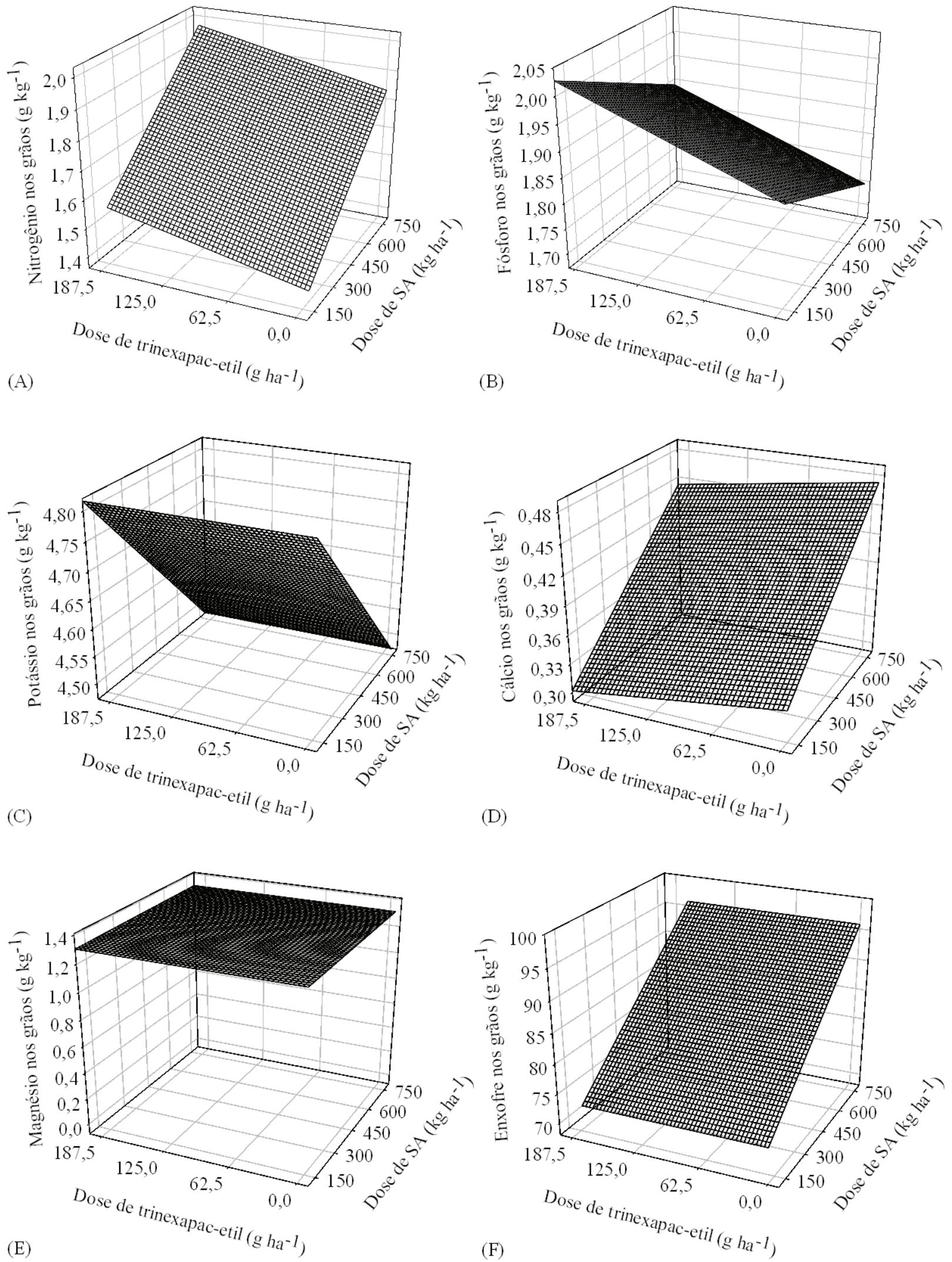

Figura 1. Concentração de macronutrientes nos grãos de trigo submetidos às doses de sulfato de amônio (SA) e trinexapac-etil: Nitrogênio (A), Fósforo (B), Potássio (C), Cálcio (D), Magnésio (E) e Enxofre (F) (Viçosa, MG, 2006). 

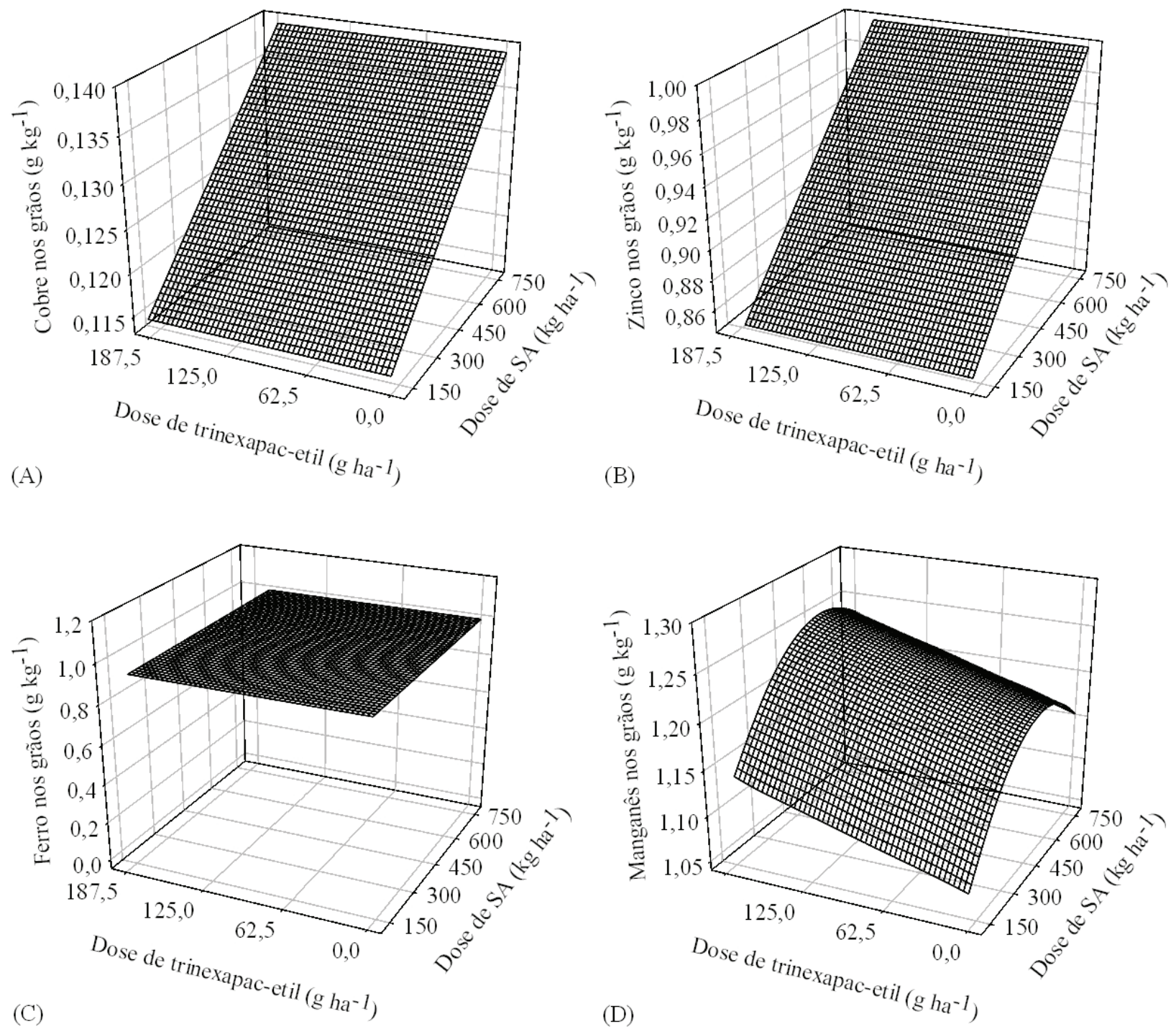

Figura 2. Concentração de micronutrientes nos grãos de trigo submetidos às doses de sulfato de amônio (SA) e trinexapac-etil: Cobre (A), Zinco (B), Ferro (C) e Manganês (D) (Viçosa, MG, 2006).

2007). Aumento do conteúdo de proteína nos grãos também foi encontrado em trigo de inverno, que recebeu aplicação de trinexapac-etil (Matysiak 2006).

A concentração de $\mathrm{P}$ nos grãos decresceu linearmente, em função das doses de SA, e aumentou linearmente, em função das doses de trinexapac-etil (Figura 1B), evidenciando que não houve redução no desenvolvimento das raízes, após aplicação do trinexapac-etil, como já havia sido sugerido por Alvarez et al. (2007). O aumento na concentração de $\mathrm{P}$, provavelmente, está relacionado ao maior enchimento de grãos, como discutido para o teor de N.

$\mathrm{O}$ decréscimo de $\mathrm{P}$, em função do $\mathrm{SA}$, difere das respostas relatadas para milho, onde doses de $\mathrm{N}$ não influenciaram (Deparis et al. 2007) ou promoveram aumento no teor de $\mathrm{P}$ nos grãos (Ferreira et al. 2001). Entretanto, Coelho et al. (2001) relataram que a aplicação de $\mathrm{N}$ reduziu os teores de $\mathrm{P}$ nos grãos de trigo, comparando-se as médias das doses com a testemunha. A resposta encontrada, neste trabalho, pode estar relacionada ao aumento no número de grãos por espiga (resultado não apresentado), isto porque o movimento do P é determinado pela demanda de carboidratos dentro da planta (Fernandes 2006). Assim, com o aumento do número de drenos, as plantas tiveram o enchimento de grãos prejudicado, devido à competição, e, consequentemente, menor quantidade de P foi translocada para os grãos. É importante res- 
saltar que altos teores de P nos grãos de trigo podem causar efeitos adversos à saúde humana (Schulthess et al. 1997).

As doses de SA promoveram decréscimo linear na concentração de $\mathrm{K}^{+}$, enquanto as doses de trinexapac-etil não influenciaram na concentração do nutriente nos grãos (Figura 1C). A resposta ao SA difere dos resultados relatados para trigo, cultivar EMBRAPA-22, em dois anos de cultivo (Coelho et al. 2001), cujos teores de $\mathrm{K}^{+}$nos grãos não foram influenciados pelas doses de N. O aumento das concentrações de $\mathrm{K}^{+}$nos grãos não é esperado, quando se aumentam as concentrações de $\mathrm{N}$, visto que o $\mathrm{K}^{+}$não faz parte dos carboidratos, principal componente dos grãos de trigo. É possível que existam características inerentes à cultivar que promovam maior ou menor acúmulo de $\mathrm{K}^{+}$e, ainda, apesar do nível do nutriente no solo estar adequado (Tabela 1), é possível que o aumento do dreno (número de grãos) possa ter influenciado esta característica. Os efeitos do trinexapac-etil estão de acordo com o esperado, pois o potássio não faz parte das moléculas que constituem os grãos, apesar de ser importante para os tecidos vegetais, por participar como cofator de enzimas e do estabelecimento do turgor celular (Taiz \& Zeiger 2004).

A concentração de cálcio nos grãos aumentou linearmente, com o aumento das doses de SA, e decresceu linearmente, com o incremento das doses de trinexapac-etil (Figura 1D). O acréscimo da concentração de $\mathrm{Ca}^{2+}$ concorda com os resultados encontrados em milho (Ferreira et al. 2001). Estes autores sugerem que esta resposta pode estar relacionada à maior necessidade de cálcio nos grãos, para formação de parede celular, de tal modo que possa suportar a maior quantidade de metabólitos translocados aos grãos, com a adubação nitrogenada. Por outro lado, a análise dos resultados evidencia que o trinexapac-etil não afeta a translocação de $\mathrm{Ca}^{2+}$ para os grãos.

As doses de SA e trinexapac-etil não influenciaram na concentração de $\mathrm{Mg}^{2+}$ nos grãos (Figura 1E). Espera-se que, com a aplicação de N, os níveis de clorofila nas folhas aumentem e, como consequência, os níveis de $\mathrm{Mg}^{2+}$ também aumentem, o que resulta em maior concentração de $\mathrm{Mg}^{2+}$ para translocação e, consequentemente, maior concentração de $\mathrm{Mg}^{2+}$ nos grãos, como encontrado em milho (Ferreira et al. 2001) e trigo (Coelho et al. 2001). No entanto, por não se tratar de nutriente constituinte das moléculas do grão, assim como o $\mathrm{K}^{+}$, os resultados são justificáveis. Além disso, havia baixa concen- tração do nutriente no solo (Tabela 1). De maneira análoga, a ausência de efeitos, em função das doses de trinexapac-etil, está relacionada à baixa demanda de $\mathrm{Mg}$ pelos grãos.

A concentração de enxofre nos grãos aumentou linearmente, com o incremento das doses de SA, mas não foi influenciada pelas doses de trinexapac-etil (Figura 1F). A resposta ao SA assemelha-se ao que foi relatado para milho (Ferreira et al. 2001) e trigo (Coelho et al. 2001). Este aumento pode ser explicado pelo aumento das doses de $\mathrm{S}$ no solo e pela sua presença nos aminoácidos cisteína, cistina e metionina (Taiz \& Zeiger 2004), uma vez que estes são componentes de proteínas e estas tendem a aumentar a sua concentração, com o aumento das doses de N. Por outro lado, esperava-se que o aumento das doses de trinexapac-etil promovesse aumento do teor de enxofre nos grãos, pois o redutor aumenta a quantidade de proteína nos grãos (Matysiak 2006). Esta ausência de resposta pode estar associada ao aumento da proteína bruta (N-total), que, apesar de ter sido significativo, teve baixo coeficiente angular (Tabela 3), ou seja, há aumento, mas este não é tão expressivo.

As concentrações de cobre e zinco nos grãos aumentaram linearmente, em função do incremento das doses de SA, mas não foram influenciadas pelas doses de trinexapac-etil (Figuras 2A e 2B).

Os incrementos de cobre e zinco, em função das doses de SA, concordam com os resultados encontrados por Coelho et al. (2001), para o aumento das doses de $\mathrm{N}$. O N promove incremento na biomassa e no desenvolvimento vegetativo, portanto, espera-se que processos fisiológicos que envolvam reações redox, como respiração e fotossíntese, também aumentem. Com isso, é esperado que a concentração de $\mathrm{Zn}$ e $\mathrm{Cu}$, na parte vegetativa, também seja aumentada, uma vez que estes nutrientes estão diretamente ligados a estas reações. Assim, sugere-se que os aumentos destes nutrientes nos grãos sejam devidos ao aumento da absorção dos mesmos e da consequente translocação. Deve-se, ainda, ressaltar que estes nutrientes podem interagir entre si, quanto à maior ou menor absorção, pois Tani \& Barrington (2005) identificaram que, em trigo, o aumento na absorção de $\mathrm{Cu}$ resulta em aumento na absorção de Zn. Por outro lado, esperava-se que o trinexapac-etil, por melhorar o enchimento de grãos, também promovesse maior translocação de $\mathrm{Cu}$ e $\mathrm{Zn}$ para os grãos, o que não ocorreu. Talvez, a redução do volu- 
me da parte aérea possa ter mantido estável o nível de reações redox e, consequentemente, a absorção e translocação destes nutrientes na planta.

A concentração de Ferro nos grãos não foi influenciada pelas doses de SA ou de trinexapac-etil (Figura 2C). As respostas às doses de $\mathrm{N}$ assemelham-se aos resultados obtidos para trigo, em dois anos de cultivo (Coelho et al. 2001). Tanto para o SA quanto para o trinexapac-etil, a ausência de efeito, provavelmente, está ligada à baixa necessidade deste nutriente na composição dos grãos, bem como à baixa mobilidade deste nutriente na planta (Fernandes 2006).

O manganês, nos grãos, respondeu de forma quadrática ao aumento das doses de SA e aumentou linearmente, com as doses de trinexapac-etil (Figura 1D). O teor de Mn nos grãos de trigo, cultivar EMBRAPA-22, decresceu linearmente, com o aumento das doses de N (Coelho et al. 2001). Estes autores sugerem que o $\mathrm{Mn}$, nos grãos, correlaciona-se, negativamente, com o teor de proteína. No entanto, os aumentos do $\mathrm{Mn}^{2+}$ nos grãos, em função das doses de trinexapac-etil e de SA, até a dose de $457 \mathrm{~kg} \mathrm{ha}^{-1}$, sugerem correlação positiva entre o Mn e as proteínas, uma vez que o N, nos grãos, estimador do nível de proteínas, aumentou com o incremento de ambos os insumos. Esta resposta pode estar ligada a fatores genéticos e é justificável, pois o Mn participa da reação de fotossíntese, que é aumentada pelo incremento nas doses de N (Marschner 1995) e pelas doses de trinexapac-etil, devido às mudanças morfológicas promovidas por este produto (Zagonel \& Fernandes 2007). Além disso, o $\mathrm{Mn}^{2+}$ pode substituir o $\mathrm{Mg}^{2+}$, em algumas funções na planta (Fernandes 2006), e, como o nível deste último nutriente estava baixo no solo, é possível que tal fenômeno tenha ocorrido. Já a queda nos níveis de $\mathrm{Mn}$, após a dose de $457 \mathrm{~kg} \mathrm{ha}^{-1}$ de N, pode estar associada ao excesso de crescimento vegetativo e consequente autosombreamento.

\section{CONCLUSÕES}

1. As doses de SA melhoraram a qualidade nutricional dos grãos de trigo, pelo incremento das concentrações de proteína (N-total), Ca, S, Cu e Zn, apesar de provocarem reduções nas concentrações de P, K e Mn (acima da dose $457 \mathrm{~kg} \mathrm{ha}^{-1}$ ) e de não influenciarem o $\mathrm{Mg}$ e o Fe.

2. O trinexapac-etil não influenciou, de maneira significativa, a composição mineral dos grãos de trigo.

\section{AGRADECIMENTOS}

Ao Conselho Nacional de Desenvolvimento Científico e Tecnológico (CNPq) e à Fundação de Amparo à

Pesquisa do Estado de Minas Gerais (Fapemig), pelas bolsas e auxílios concedidos.

\section{REFERÊNCIAS}

ALVAREZ, R. C. F. et al. Influência do etil-trinexapac no acúmulo, na distribuição de nitrogênio $\left({ }^{15} \mathrm{~N}\right)$ e na massa de grãos de arroz de terras altas. Revista Brasileira de Ciência do Solo, Viçosa, v. 31, n. 6, p. 1487-1496, 2007.

BERTI, M. et al. Produtividade de cultivares de trigo em função do trinexapac-ethyl e doses de nitrogênio. Scientia Agraria, Curitiba, v. 8, n. 2, p. 127-134, 2007.

BUZETTI, S. et al. Resposta de cultivares de arroz a doses de nitrogênio e do regulador de crescimento cloreto de clormequat. Pesquisa Agropecuária Brasileira, Brasília, DF, v. 41, n. 12, p. 1731-1737, 2006.

COELhO, M. A. O. et al. Composição mineral e exportação de nutrientes pelos grãos do trigo irrigado e submetido a doses crescentes e parceladas de adubo nitrogenado. Revista Ceres, Viçosa, v. 48, n. 275, p. 8194, 2001.

DEPARIS, G. A. et al. Espaçamento e adubação nitrogenada e potássica em cobertura na cultura do milho. Acta Scienciarum Agronomy, Maringá, v. 29, n. 4, p. 517 525, 2007.

EMPRESA BRASILEIRA DE PESQUISA AGROPECUÁRIA (Embrapa). Manual de métodos de análises de solo. 2. ed. Rio de Janeiro: Embrapa, 1997.

ESPINDULA, M. C. et al. Efeitos de reguladores de crescimento na elongação do colmo de trigo. Acta Scienciarum Agronomy, Maringá, v. 32, n. 1, p. 109-116, 2010.

ESPINDULA, M. C. et al. Use of growth retardants in wheat. Planta Daninha, Viçosa, v. 27, n. 2, p. 379-387, 2009.

FERNANDES, M. S. Nutrição mineral de plantas. Viçosa: Sociedade Brasileira de Ciência do Solo, 2006.

FERREIRA, A. C. B. et al. Características agronômicas e nutricionais do milho adubado com nitrogênio, molibdênio e zinco. Scientia Agricola, Piracicaba, v. 58, n. 1, p. 131138, 2001.

GOBI, R. et al. Growth and photosynthetic characteristics as affected by triazoles in Amorphophallus campanulatus Blume. General and Applied Plant Physiology, Saskatoon, v. 31, n. 3-4, p. 171-180, 2005. 
GOMES JÚNIOR, F. G. et al. Teor de proteína em grãos de feijão em diferentes épocas e doses de cobertura nitrogenada. Acta Scientiarum Agronomy, Maringá, v. 27, n. 3, p. 455-459, 2005.

HECKMAN, N. L. et al. Influence of trinexapac-ethyl on respiration of isolated wheat mitochondria. Crop Science, Madison, v. 42, n. 2, p. 423-427, 2002.

LINZMEYER JUNIOR, R. et al. Influência de retardante vegetal e densidades de plantas sobre o crescimento, acamamento e produtividade da soja. Acta Scientiarum Agronomy, Maringá, v. 30, n. 3, p. 373-379, 2008.

MARSCHNER, H. Mineral nutrition of higher plants. 2. ed. London: Academic Press, 1995.

MATYSIAK, K. Influence of trinexapac-ethyl on growth and development of winter wheat. Journal of Plant Protection Research, Poznań, v. 46, n. 2, p.133-143, 2006.

ORTIZ-MONASTERIO, J. I. et al. Enhancing the mineral and vitamin content of wheat and maize through plant breeding. Journal of Cereal Science, Kidlington, v. 46, n. 3, p. 293-307, 2007.

RADEMACHER, W. Growth retardants: effects on gibberellin biosynthesis and other metabolic pathways. Annual Review of Plant Physiology and Plant Molecular Biology, Palo Alto, n. 51, p. 51-31, 2000.

RYAN, J. et al. Rainfed wheat-based rotations under Mediterranean conditions: crop sequences, nitrogen fertilization, and stubble grazing in relation to grain and straw quality. European Journal of Agronomy, Bologna, v. 28, n. 2, p. 112-118, 2008.
SCHULTHESS, U. et al. Yield-independent variation in grain nitrogen and phosphorus concentration among Ethiopian wheats. Agronomy Journal, Madison, v. 89, n. 3, p. 497-506, 1997.

SOBRINHO, J. S.; SOUZA, M. A. Origem, descrição botânica e desenvolvimento do trigo. Informe Agropecuário, Belo Horizonte, v. 9, n. 97, p. 9-13, 1983.

STACHECKI, S. et al. Adjuvant effects on plant growth regulators in winter wheat. Journal of Plant Protection Research, Poznań, v. 44, n. 4, p. 365-371, 2004.

TAIZ, L.; ZEIGER, E. Fisiologia vegetal. 3. ed. Porto Alegre: Artmed, 2004.

TANI, F. H.; BARRINGTON, S. Zinc and copper uptake by plants under two transpiration rates: Part I. Wheat (Triticum aestivum L.). Environmental Pollution, Essex, v. 138, n. 3, p. 538-547, 2005.

TRINDADE, M. G. et al. Nitrogênio e água como fatores de produtividade do trigo no Cerrado. Revista Brasileira de Engenharia Agrícola e Ambiental, Campina Grande, v. 10, n. 1, p. 24-29, 2006.

VIANA, R. S. et al. Efeito da aplicação de maturadores químicos na cultura da cana-de-açúcar (Saccharum spp.) variedade SP81-3250. Acta Scientiarum Agronomy, Maringá, v. 30, n. 1, p. 65-71, 2008.

ZAGONEL, J.; FERNANDES, E. C. Doses e épocas de aplicação do redutor de crescimento afetando cultivares de trigo em duas doses de nitrogênio. Planta Daninha, Viçosa, v. 25, n. 2, p. 331-339, 2007. 